\title{
Regioselectivity of oxidation by a polysaccharide monooxygenase from Chaetomium thermophilum
}

\author{
Chen Chen, Jinyin Chen, Zhigang Geng, Meixia Wang, Ning Liu and Duochuan Li
}

\begin{abstract}
Background: Polysaccharide monooxygenases (PMOs) of the auxiliary activity 9 (AA9) family have been reported to oxidize C1, C4, and C6 positions in cellulose. However, currently no direct evidence exists that PMOs oxidize C6 positions in cellulose, and molecular mechanism of C1, C4 and C6 oxidation is unclear.

Results: In this study, a PMO gene (Ctpmo 1) belonging to AA9 was isolated from Chaetomium thermophilum and successfully expressed and correctly processed in Pichia pastoris. A simple and effective chemical method of using $\mathrm{Br}_{2}$ to oxidize CtPMO1 reaction products was developed to directly identify C4- and C6-oxidized products by matrix-assisted laser desorption/ionization-time-of-flight tandem mass spectrometry (MALDI-TOF-MS). The PMO (CtPMO1) cleaves phosphoric acid-swollen cellulose (PASC) and celloheptaose, resulting in the formation of oxidized and nonoxidized oligosaccharides. Product identification shows that the enzyme can oxidize C1, C4, and C6 in PASC and cello-oligosaccharides. Mutagenesis of the aromatic residues Tyr27, His64, His157 and residue Tyr206 on the flat surface of CtPMO1 was carried out using site-directed mutagenesis to form the mutated enzymes Y27A, H64A, H157A, and Y206A. It was demonstrated that Y27A retained complete activity of C1, C4, and C6 oxidation on cellulose; Y206A retained partial activity of $\mathrm{C} 1$ and $\mathrm{C} 4$ oxidation but completely lost activity of $\mathrm{C} 6$ oxidation on cellulose; $\mathrm{H64A}$ almost completely lost activity of $\mathrm{C} 1, \mathrm{C} 4$, and $\mathrm{C} 6$ oxidation on cellulose; and $\mathrm{H} 157 \mathrm{~A}$ completely lost activity of $\mathrm{C} 1, \mathrm{C} 4$, and $\mathrm{C} 6$ oxidation on cellulose.
\end{abstract}

Conclusions: This finding provides direct and molecular evidence for $C 1, C 4$, especially $C 6$ oxidation by lytic polysaccharide monooxygenase. CtPMO1 oxidizes not only C1 and C4 but also C6 positions in cellulose. The aromatic acid residues His64, His157 and residue Tyr206 on CtPMO1 flat surface are involved in activity of C1, C4, C6 oxidation.

Keywords: Chaetomium thermophilum, Auxiliary activity family 9 (AA9), Polysaccharide monooxygenase (PMO), Regioselectivity of oxidation, C1, C4 and C6 oxidation

\section{Background}

Cellulose is one of the most abundant renewable carbohydrates on earth. Enzymatic degradation of cellulose to glucose has great potential for biofuel production [1]. This enzymatic degradation is thought to be accomplished by the synergistic action of three classes of cellulases: endocellulases, exocellulases, and beta-glucosidases [2]. However, the low degradation efficiency and the high cost of cellulases are major barriers to economical biofuel

*Correspondence: lidc20@163.com

Department of Mycology, Shandong Agricultural University, Taian 271018, Shandong, China production [3]. Recently, a new class of cellulose-degrading enzymes, called $\mathrm{Cu}^{2+}$-dependent lytic polysaccharide monooxygenases (PMOs) [4], have been discovered and are attracting increasing interest because their oxidative degradation of cellulose dramatically boosts cellulase activity in cellulose hydrolysis [5-8].

Based on their amino acid sequence similarities, PMO enzymes are classified into four families: auxiliary activity 9 (AA9), auxiliary activity 10 (AA10), auxiliary activity 11 (AA11), and auxiliary activity 13 (AA13) [4, 9, 10]. With a plethora of biochemical, structural, functional, and regioselective data available, PMOs from AA9 have 
been studied intensively in fungi $[7,8,11-18]$. From a structural perspective, the 3-D structure of AA9 PMOs, to perform cleavage, displays a beta-sheet fold with a flat substrate-binding surface that differs from traditional cellulases in that it does not show a substrate-binding cleft (groove, crevice, or tunnel). The flat surface of an AA9 PMO binds cellulose molecules and contains at its center an absolutely conserved $\mathrm{N}$-terminal histidine residue where a copper ion is confirmed to bind tightly [5, $7,14,19]$. With respect to the oxidation position of substrate molecules, AA9 PMO enzymes have demonstrated striking differences in regioselectivities, most possibly because of their multigenicity $[4,11]$. The enzymes oxidize the $\mathrm{C} 1$ carbon atom of glucose, but may also oxidize $\mathrm{C} 4$ or even $\mathrm{C6}$. Through an elimination reaction, the $\mathrm{C} 1$ and $\mathrm{C} 4$ oxidation results in two direct cleavage sites of the glucosidic bond. The $\mathrm{C} 1$ oxidation leads to the formation of sugar lactone, which is spontaneously hydrolyzed into aldonic acid, and the $\mathrm{C} 4$ and $\mathrm{C} 6$ oxidations lead to the formation of C4-ketoaldose $[8,11,12,16,17,20,21]$ and C6-hexodialdose $[7,15]$, respectively. However, no direct evidence demonstrates the presence of C6-hexodialdose in PMO's reaction products [12, 17]. Although PMO C6 oxidation has been suggested based only on mass measurements $[7,15]$, mass measurements alone are not enough to confirm that PMOs can oxidize C6 positions of cellulose, because C6-hexodialdose has the same molecular weight as C4-ketoaldose [22]. Because PMO C6 oxidation has not been rigorously demonstrated [12, 17], the described three groups of AA9 PMOs (PMO1 for $\mathrm{C} 1$ oxidation, $\mathrm{PMO} 2$ for $\mathrm{C} 4$ oxidation, and $\mathrm{PMO} 3$ for $\mathrm{C} 1$ and $\mathrm{C} 4$ oxidation) are not involved in $\mathrm{C} 6$ oxidation [17]. Currently, PMO C6 oxidation has remained elusive and considerable academic debate is being conducted regarding PMO C6 oxidation [11, 12, 17, 21, 22].

Chaetomium thermophilum is a thermophilic fungus and can grow in temperatures up to $60{ }^{\circ} \mathrm{C}$. The thermophilic fungus has been suggested as a model organism for biochemical and prospective structural analyses of eukaryotic macromolecular complexes and biotechnological applications of thermostable eukaryotic proteins $[23,24]$. C. thermophilum genome analysis reveals 19 genes encoding putative AA9 PMOs (http://www.funga lgenomics.cn). In the present paper, we provide direct evidence that an AA9 PMO from $C$. thermophilum displays oxidation at $\mathrm{C} 1, \mathrm{C} 4$, and $\mathrm{C} 6$ positions of cellulose, especially at $\mathrm{C} 6$ positions of cellulose.

\section{Results}

\section{CtPMO1 expression and purification}

We amplified a gene (KC441882) with only one amino acid difference from the Chath2p7_007187 gene of $C$. thermophilum genome by polymerase chain reaction (PCR) with a pair of specific primers from the CGMCC3.17990 strain of C. thermophilum from China (Additional file 1: Table S1). The KC441882 gene was designated as Ctpmo1, encoding a putative AA9 PMO protein, CtPMO1. The CtPMO1 protein was predicted to be a secreted enzyme with a 17-amino acid potential signal peptide. The mature CtPMO1 protein is composed of 229 amino acids with a calculated molecular weight of $24.63 \mathrm{kDa}$. Like most AA9 proteins, CtPMO1 has only a catalytic domain and no additional modules [20].

To obtain the CtPMO1 protein with a native $\mathrm{N}$-terminus, we used the plasmid pPICZ $\alpha \mathrm{A}$ for Ctpmo1 expression in $P$. pastoris. After induction with methanol, we purified the expressed $\mathrm{Cu}^{2+}$-loaded CtPMO1 using nickel affinity chromatography from the $\mathrm{Cu}^{2+}$-containing culture filtrate of $P$. pastoris transformed with the recombinant plasmid pPICZ $\alpha \mathrm{A} /$ Ctpmo1 (Additional file 1: Figure S1). Using SDS-PAGE, we estimated the molecular weight of the purified recombinant CtPMO1, which contains a $6 \times$ His tag and a myc tag $(2.68 \mathrm{kDa})$ at the C-terminal, to be approximately $27.5 \mathrm{kDa}$. Subtracting $2.68 \mathrm{kDa}$ brought this value very close to the $24.63 \mathrm{kDa}$, we calculated from the deduced amino acid sequence of CtPMO1. We identified the $\mathrm{N}$-terminal amino acid sequence of CtPMO1 using LC-MS/MS to be HAIFQK (Additional file 1: Figure S2), indicating that CtPMO1 was correctly processed in P. pastoris. As in the case of other PMOs expressed in P.pastoris [16, 25], the $\mathrm{N}$-terminal His residue in CtPMO1 is not methylated.

\section{Identification of CtPMO1 soluble reaction products}

To identify products of CtPMO1, we performed soluble product assay on phosphoric acid-swollen cellulose (PASC) using TLC and MALDI-TOF-MS analysis. TLC analysis showed that treatment of PASC with CtPMO1 mainly produced cello-oligosaccharides with a degree of polymerization (DP) from $\mathrm{DP}_{2}$ to $\mathrm{DP}_{6}$ (Fig. 1). MALDITOF-MS analysis showed that treatment of PASC with CtPMO1 produced a series of molecular ions with $\mathrm{m} / \mathrm{z}$ corresponding to cello-oligosaccharide products with a $\mathrm{DP}$ from $\mathrm{DP}_{3}$ to $\mathrm{DP}_{6}$ (Fig. 2). Importantly, the molecular ions corresponding to various oxidized oligosaccharides, C1-oxidized oligosaccharides (aldonic acid, $\mathrm{m} / z+16$ ) and C4- or C6-oxidized oligosaccharides (C4-ketoaldose or C6-hexodialdose, $m / z-2$ ), were observed, indicating the nature of oxidative enzymes. Additionally, minor double $\mathrm{C} 4$ and $\mathrm{C} 6$ oxidized oligosaccharides $(\mathrm{m} / \mathrm{z}-4)$ and double $\mathrm{C} 1$ and $\mathrm{C} 4$ or $\mathrm{C} 6$ oxidized oligosaccharides $(m / z+14)$ were observed. MS/MS fragmentation of the highest peak with $m / z$ value of 525 from MALDI-TOFMS analysis, corresponding to the C6 or C4-oxidized products $\left(\mathrm{DP}_{3}-2\right)$, showed the presence of nonoxidized 


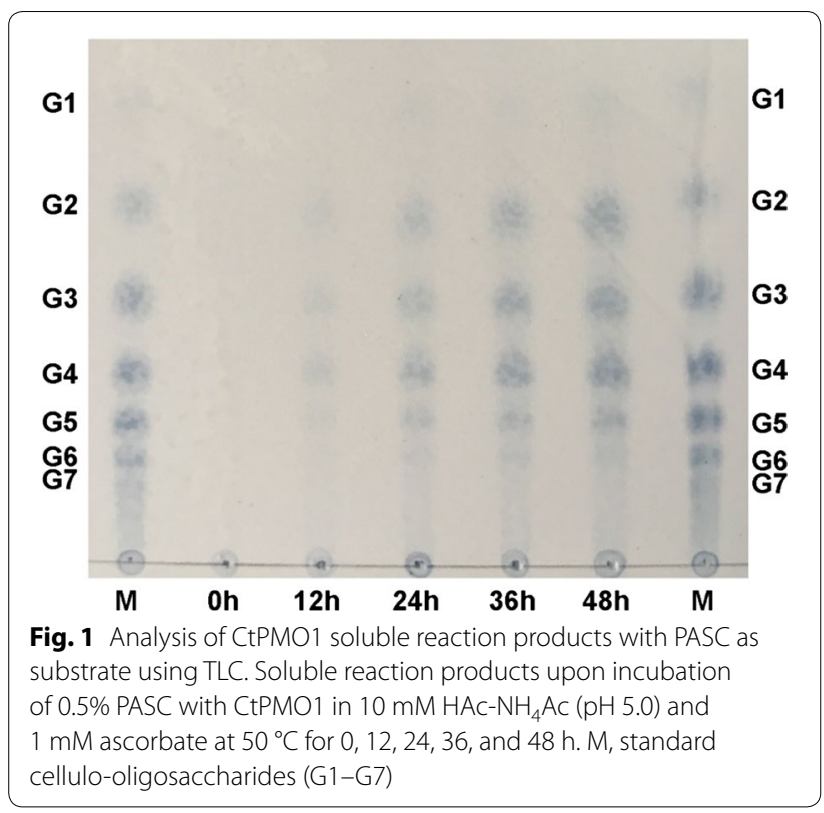

fragmentation ions and $\mathrm{C} 6$ or C4-oxidized fragmentation ions (Additional file 1: Figure S3, S4, Table S2). In particular, we observed that the potential fragmentation ions oxidized only at $\mathrm{C} 6$, indicating that the $\mathrm{C} 6$ positions could be modified.

Because NMR has been applied to identify galactose oxidation at C6 positions [26], it was performed to confirm C6-oxidized cellulo-oligosaccharides
(C6-hexodialdose) in CtPMO1 soluble reaction products. As expected, ${ }^{1} \mathrm{H}$ NMR spectrum of CtPMO1 soluble reaction products displayed an aldehyde proton signal at $\delta 8.39$ (Additional file 1: Figure S5). The anomeric resonance at $\delta 8.39$ is close to the anomeric resonances at $\delta 9.19$ and 9.50 that are assigned to the aldehyde proton of two C6-oxidized galactose products [26].

To confirm CtPMO1 $\mathrm{C} 4$ and $\mathrm{C} 6$ oxidation, we performed another chemical method, using $\mathrm{Br}_{2}$ to oxidize CtPMO1 soluble reaction products for MALDI-TOFMS analysis. Based on the chemical method, if CtPMO1 products had C1-oxidized oligosaccharides $(m / z+16)$, they would not be oxidized by $\mathrm{Br}_{2}$; if CtPMO1 products had C4-oxidized oligosaccharides (C4-ketoaldose, $m / z-2$ ), they would be oxidized by $\mathrm{Br}_{2}$ to form $\mathrm{C} 4$ and $\mathrm{C} 1$-oxidized oligosaccharides (4-keto-aldonic acid, $m / z+14)$; if CtPMO1 products had C6-oxidized oligosaccharides (C6-hexodialdose, $m / z-2$ ), they would be oxidized by $\mathrm{Br}_{2}$ to form C6- and C1-oxidized cellooligosaccharides $(\mathrm{m} / z+30)$; and if CtPMO1 products had C4- and C6-oxidized oligosaccharides $(\mathrm{m} / z-4)$, they would be oxidized by $\mathrm{Br}_{2}$ to form C4-, C6- and C1-oxidized cello-oligosaccharides $(m / z+28)$ (Fig. 3a). As expected, we observed the molecular ions corresponding to various oxidized oligosaccharides, C4and C1-oxidized oligosaccharides $(m / z+14)$, C6- and C1-oxidized oligosaccharides $(m / z+30)$, and C6-, C4-, and C1-oxidized oligosaccharides $(m / z+28)$ in

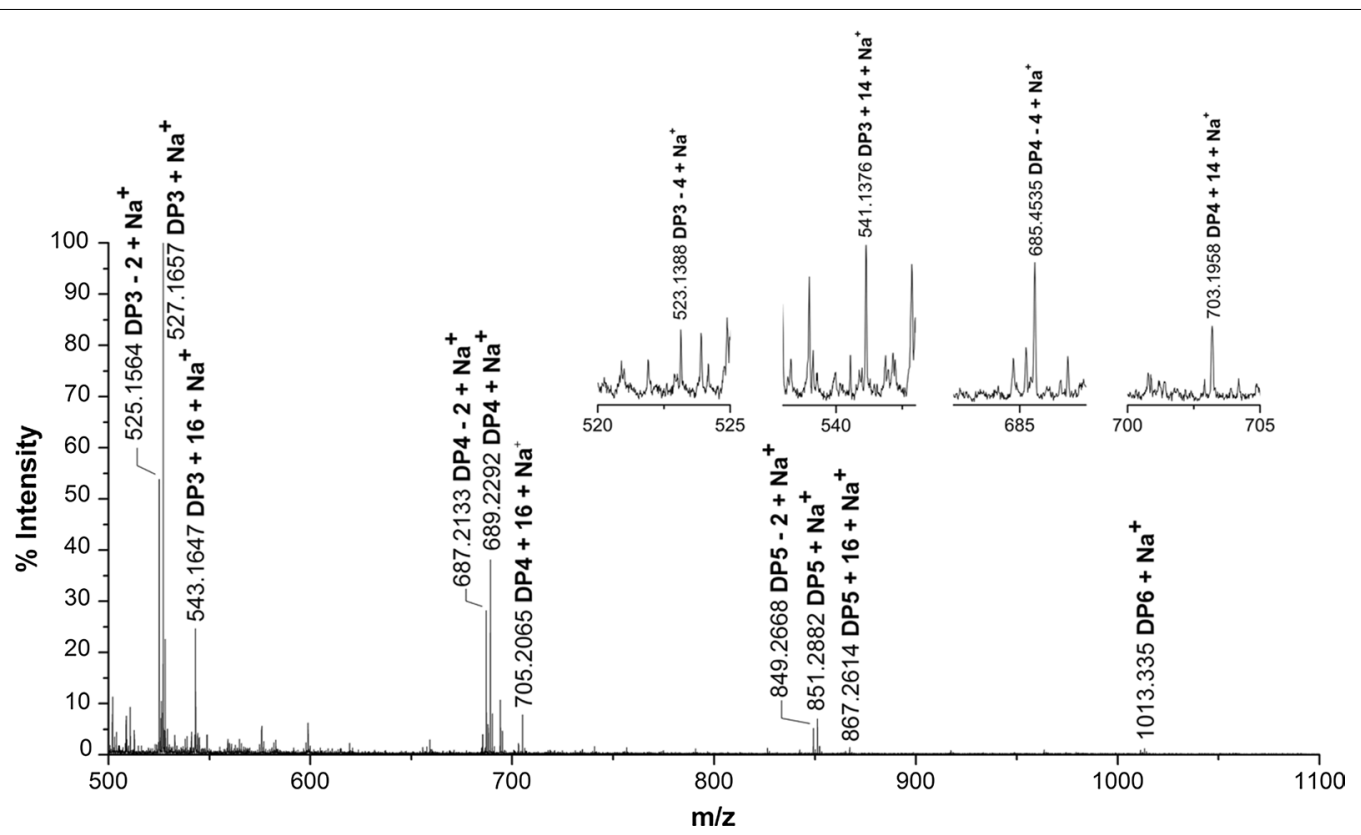

Fig. 2 Identification of CtPMO1 soluble reaction products with PASC as substrate using MALDI-TOF-MS. Soluble reaction products upon incubation

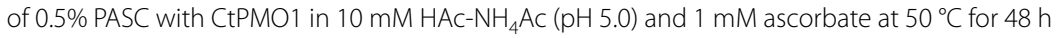


a

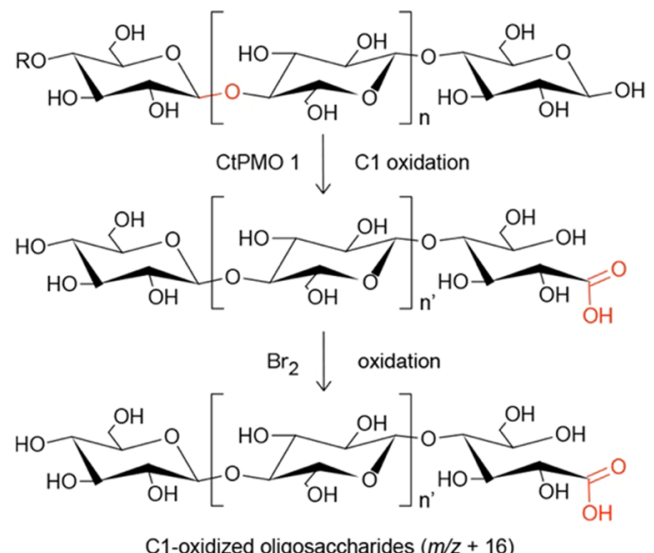

$\left.{ }_{\mathrm{OH}}^{\mathrm{RO}} \mathrm{O}_{\mathrm{OH}}^{\mathrm{OHO}}\right]_{\mathrm{OH}}^{\mathrm{OHO}}$

CtPMO $1 \downarrow$ C1 oxidation

CtPMO $1 \downarrow$ C4 oxidation



$\mathrm{Br}_{2} \downarrow$ oxidation

$\mathrm{Br}_{2} \downarrow$ oxidation

$\underbrace{\mathrm{OH}}_{\mathrm{OH}}\left[\frac{\mathrm{OH}}{\mathrm{O}}\right]_{\mathrm{OH}}^{\mathrm{OH}} \underbrace{\mathrm{OH}}_{\mathrm{OH}}$

-oxidized oligosaccharides $(m / z+16)$

C1/C4-oxidized oligosaccharides $(m / z+14)$

CtPMO $1 \downarrow_{\mathrm{C} 4 / \mathrm{C} 6 \text { oxidation }}$

管

$\mathrm{Br}_{2} \downarrow$ oxidation $\quad \mathrm{Br}_{2} \downarrow$ oxidation

C1/C4/C6-oxidized oligosaccharides $(\mathrm{m} / \mathrm{z}+28) \mathrm{OH}$

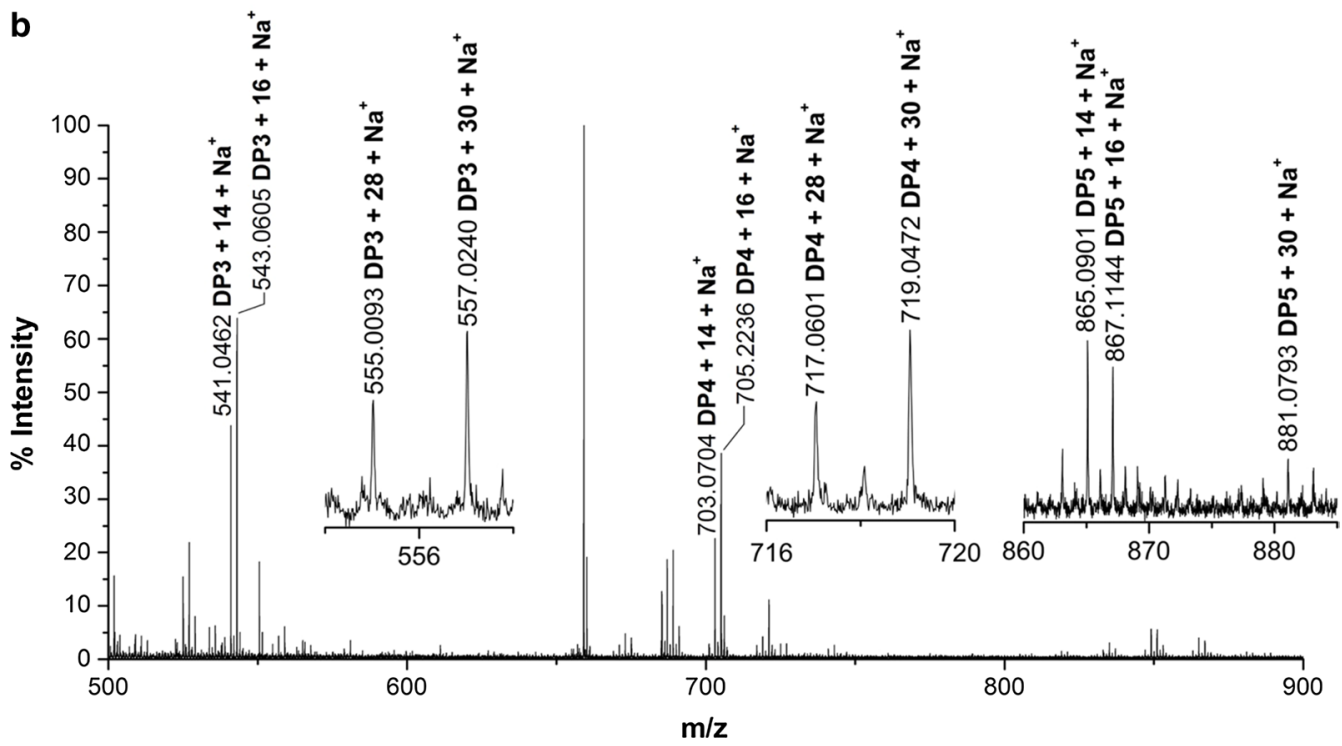

Fig. 3 Identification of CtPMO1 soluble reaction products oxidized by $\mathrm{Br}_{2}$ with PASC as substrate using MALDI-TOF-MS. Reaction pathway for oxidation of cellulose by $\mathrm{CtPMO} 1$ followed $\mathrm{Br}_{2}$ oxidation $(\mathbf{a})$ and reaction products oxidized by $\mathrm{Br}_{2}(\mathbf{b})$. C1-oxidized oligosaccharides $(\mathrm{m} / \mathrm{z}+16)$, C4- and C1-oxidized oligosaccharides ( $\mathrm{m} / \mathrm{z}+14)$, C1- and C6-oxidized oligosaccharides ( $\mathrm{m} / \mathrm{z}+30)$, and C1-, C6- and C4-oxidized oligosaccharides $(m / z+28)$ 
CtPMO1 soluble reaction products oxidized by $\mathrm{Br}_{2}$ using MALDI-TOF-MS analysis (Fig. 3b). The proportion of C6-oxidized oligosaccharides $(\mathrm{m} / z+30)$ is about $1 / 10-1 / 5$ of C4-oxidized oligosaccharides $(\mathrm{m} / z$ $+14)$, and the proportion of C6-oxidized oligosaccharides $(m / z+30)$ and $C 4$ - and C6-oxidized oligosaccharides $(m / z+28)$ is about $1 / 6-1 / 3$ of C4-oxidized oligosaccharides $(m / z+14)$, indicating that C4-oxidized oligosaccharides is predominant in CtPMO1 soluble reaction products.

\section{CtPMO1 C4- and C1-oxidized products are also present} in its insoluble reaction products

To confirm whether CtPMO1 products also exist in its insoluble reaction products (residual PASC), CtPMO1 insoluble reaction products hydrolyzed by endo1,4-beta-glucanase followed by $\mathrm{Br}_{2}$ oxidation were identified using MALDI-TOF-MS analysis (Fig. 4). Just as expected, nonoxidized cello-oligosaccharides $(m / z+0)$, C1-oxidized oligosaccharides $(\mathrm{m} / z+16)$ and $C 4$ - or C6-oxidized oligosaccharides $(m / z-2)$ were released

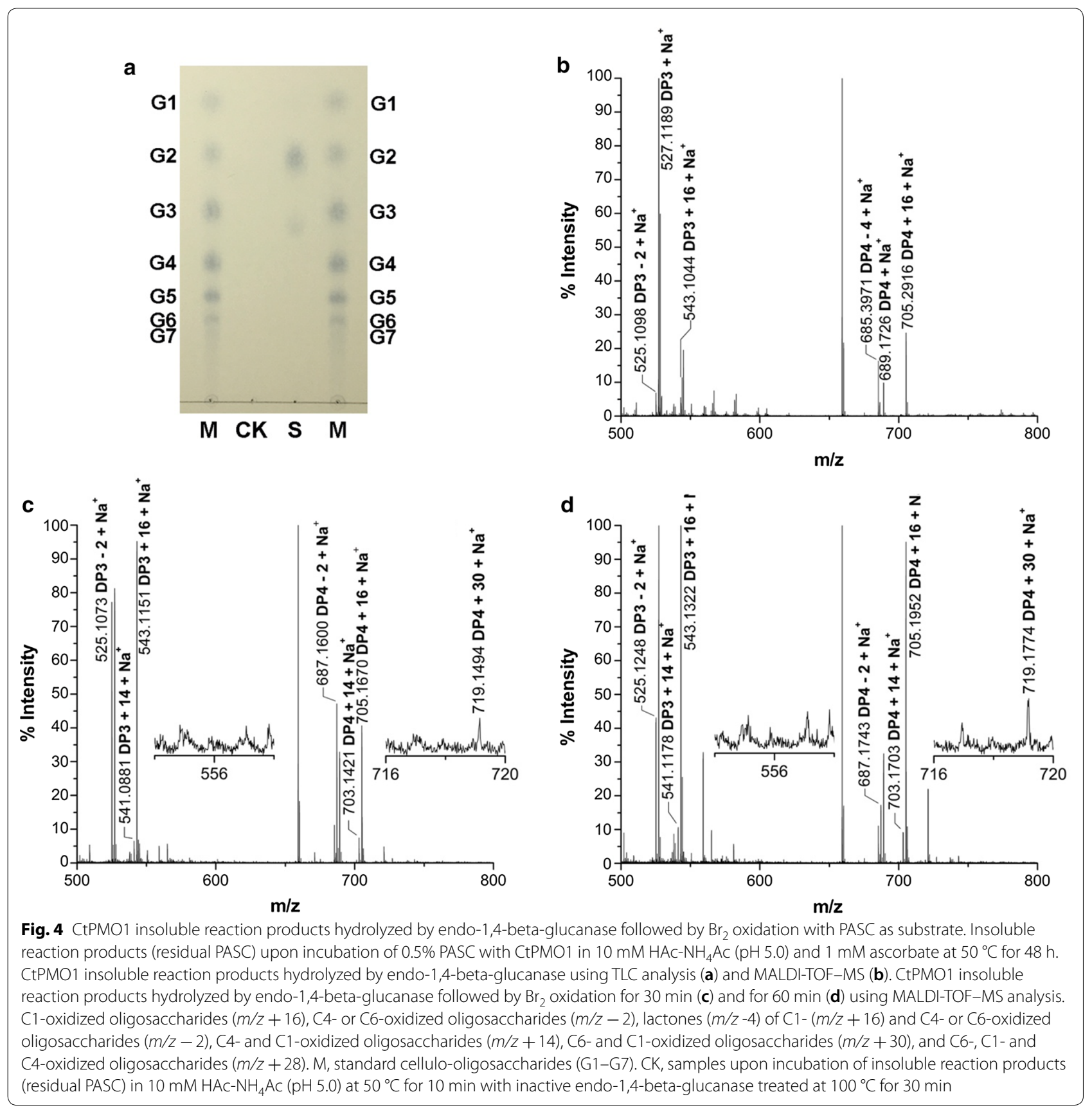


from CtPMO1 insoluble reaction products hydrolyzed by endo-1,4-beta-glucanase (Fig. 4a, b). Unexpectedly, oxidized oligosaccharides with $\mathrm{DP}_{4}(\mathrm{~m} / z-4)$ were obviously observed in CtPMO1 insoluble reaction products hydrolyzed by endo-1,4-beta-glucanase. After $\mathrm{Br}_{2}$ oxidation, we observed the main molecular ions corresponding to C1-oxidized oligosaccharides $(m / z+16)$ and C4- and C1-oxidized oligosaccharides $(\mathrm{m} / z+14)$ and the minor molecular ions corresponding to $\mathrm{C} 6$ - and C1-oxidized oligosaccharides with $\mathrm{DP}_{4}(m / z+30)$, but failed to observe molecular ions corresponding to C6and C1-oxidized oligosaccharides with $\mathrm{DP}_{3}(m / z+30)$ and C6-, C4-, and C1-oxidized oligosaccharides $(\mathrm{m} / z$ $+28)$, in CtPMO1 insoluble reaction products hydrolyzed by endo-1,4-beta-glucanase followed by $\mathrm{Br}_{2}$ oxidation for $30 \mathrm{~min}$ (Fig. 4c) and $60 \mathrm{~min}$ (Fig. 4d). The absence of the molecular ions corresponding to C6-, C4-, and C1-oxidized oligosaccharides $(\mathrm{m} / z+28)$ shows that the oxidized oligosaccharides with $\mathrm{DP}_{4}(m / z-4)$ in CtPMO1 insoluble reaction products hydrolyzed by endo-1,4-betaglucanase are lactones $(m / z-2)$ of $\mathrm{C} 4$ or C6-oxidized $(m / z-2)$ aldonic acid $(m / z+16)$ rather than C6- and C4-oxidized oligosaccharides $(m / z-4)$. These data indicate that C6-oxidized products are minor in CtPMO1 insoluble reaction products. It should be pointed out that the molecular ion peaks $(m / z-2)$ dramatically increased, but the molecular ion peaks $(m / z+14$ and +30$)$ did not obviously increase, in CtPMO1 insoluble reaction products hydrolyzed by endo-1,4-beta-glucanase followed by $\mathrm{Br}_{2}$ oxidation. The most possible reason for this is that the molecular ion peaks $(m / z-2)$ correspond to lactones $(m / z-2)$ of C1-oxidized oligosaccharides (aldonic acid, $m / z+16$ ), which are largely produced from nonoxidized oligosaccharides by $\mathrm{Br}_{2}$ oxidation and easily converted to their lactones $(m / z-2)$ in solution.

CtPMO1 can C1-, C4-, and C6-oxidize soluble celloheptaose To confirm C1, C4, and C6 oxidation of CtPMO1 on soluble cello-oligosaccharides, we used celloheptaose as substrates of CtPMO1 to generate oxidized cellulo-oligosaccharides. MALDI-TOF-MS/MS analysis confirmed the presence of $\mathrm{C} 1$-oxidized oligosaccharides (aldonic acid, $m / z+16)$ and C6- or C4-oxidized oligosaccharides (C6-hexodialdose or C4-ketoaldose, $m / z-2$ ) upon incubating CtPMO1 with celloheptaose (Fig. 5a). Like CtPMO1 soluble reaction products oxidized by $\mathrm{Br}_{2}$ with PASC as substrate, we also observed the molecular ions corresponding to $\mathrm{C} 4$ - and $\mathrm{C} 1$-oxidized oligosaccharides $(\mathrm{m} / z+14)$, C6- and C1-oxidized oligosaccharides $(\mathrm{m} / z$ +30 ), and C6-, C4- and C1-oxidized oligosaccharides $(m / z+28)$, in CtPMO1 reaction products oxidized by $\mathrm{Br}_{2}$ with celloheptaose as substrate using MALDI-TOF-MS analysis (Fig. 5b), indicating that CtPMO1 can oxidize C4, $\mathrm{C} 1$ and $\mathrm{C} 6$ positions of soluble oligosaccharides.

\section{Structural model of CtPMO1}

To understand the molecular basis of CtPMO1 C1, $\mathrm{C} 4$ and $\mathrm{C} 6$ oxidation, the 3-D structure of its catalytic domain was predicted on the basis of known 3-D structures of PMO proteins using homology modeling [5, $7,14,19,27]$. CtPMO1 shares a high identity of $64.32 \%$ with a PMO (NcLPMO9C) of Neurospora crassa (Additional file 1: Figure S6), whose 3-D structure (PDB id 4D7U) has been reported [27]. Therefore, the homology model of CtPMO1 was obtained using NCLPMO9C as a template. The homology model shows that three highly conserved amino acid residues, His1, His83 and Tyr168, are clustered at the flat surface near the $\mathrm{N}$-terminus of CtPMO1, and four aromatic residues Tyr27, His64, His157 and Tyr206 (two conserved residues His157 and Tyr206, and two varied residues Tyr27, His64) are present on the flat surface of CtPMO1 (Additional file 1: Figure S7). The N-terminal amino group $(2.3 \AA)$, the $\mathrm{N} \delta$ of His1 (2.2 $\AA$ ), and the $\mathrm{N} \varepsilon$ of His83 (2.0 $\mathrm{A}$ ) form a copper ion-binding site (a histidine-brace). The highly conserved residue Tyr168 is buried and lies in the protein-facing axial position with a distance of $3.0 \AA$ from the copper to the oxygen atom of the Tyr168 side chain. The three highly conserved residues His1, His83, and Tyr168 coordinate the copper ion essential for catalysis $[11,27]$. The role in catalytic activity of the aromatic residues Tyr27, His64, His157, and Tyr206 on the flat surface of CtPMO1 remains unclear (Additional file 1: Figure S8).

\section{Role of the aromatic residues Tyr27, His64, His 157 and Tyr206 on the flat surface of CtPMO1}

To determine whether the aromatic residues Tyr27, His64, His157 and Tyr206 on the flat surface of CtPMO1 are involved in catalytic activity of $\mathrm{C} 1, \mathrm{C} 4$ and $\mathrm{C} 6$ oxidation, mutation of the four residues of the wild-type CtPMO1 enzyme (WT) was carried out using sitedirected mutagenesis to form four mutated enzymes: Y27A, H64A, H157A and Y206A. TLC analysis of soluble reaction products showed that cello-oligosaccharides were observed in Y27A, a minor amount of cello-oligosaccharides were observed in Y206A, and no cello-oligosaccharides were observed in H64A and H157A (Fig. 6). MALDI-TOF-MS analysis showed that C1-oxidized $(m / z+16)$ and C4- or C6-oxidized $(m / z-2)$ cello-oligosaccharides were observed in Y27A and Y206A, a minor amount of $\mathrm{C} 1$-oxidized $(\mathrm{m} / \mathrm{z}+16)$ and C4- or C6-oxidized $(m / z-2)$ cello-oligosaccharides were observed in H64A, and no oxidized cello-oligosaccharides were observed in H157A (Fig. 7). 


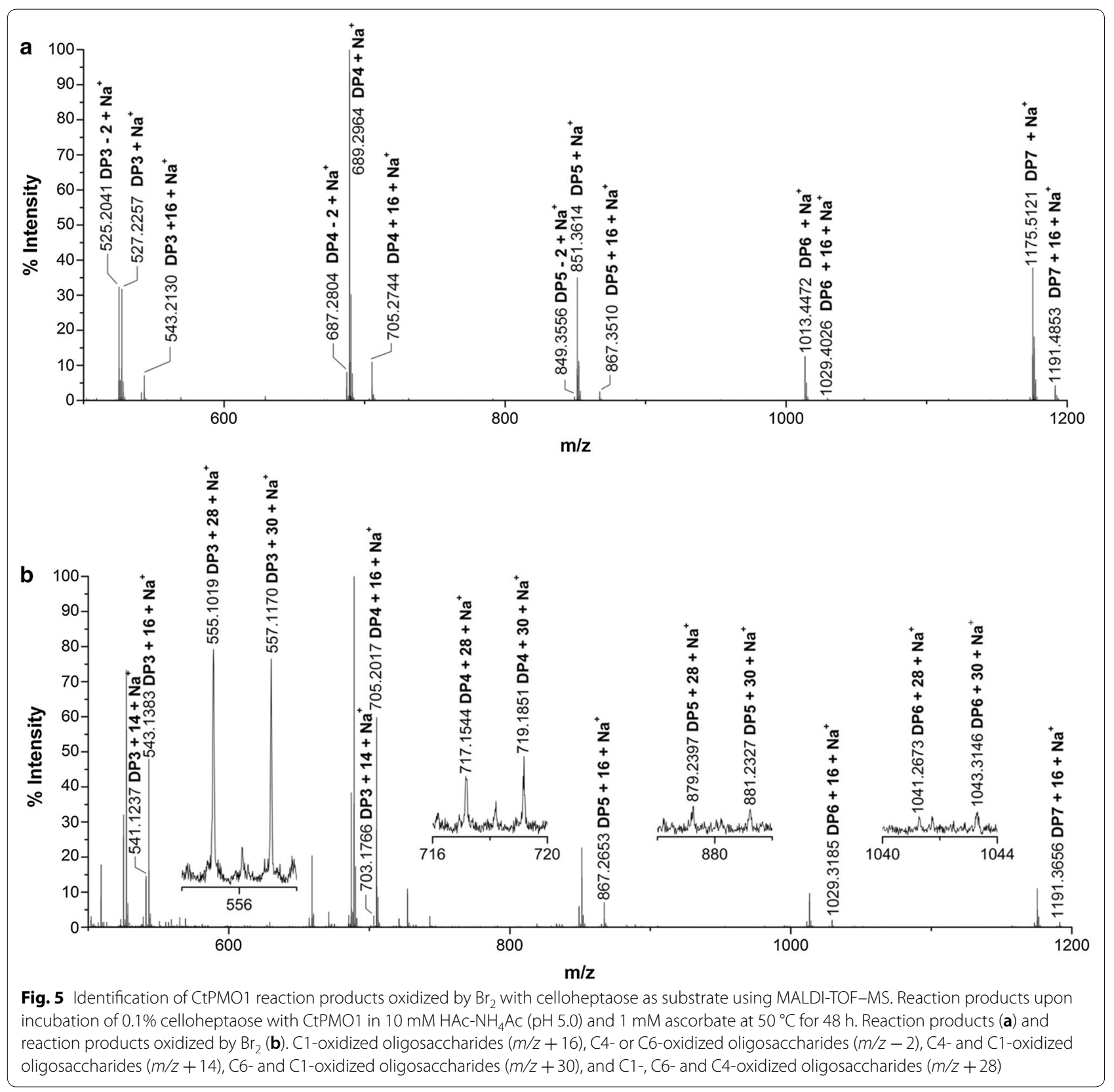

To confirm the involvement of the residues Tyr27, His64, His157 and Tyr206 of CtPMO1 in C4 and C6 oxidation, soluble reaction products of the mutated enzymes were oxidized by $\mathrm{Br}_{2}$ for MALDI-TOF-MS analysis as the WT enzyme. As expected, C4- and C1-oxidized oligosaccharides $(\mathrm{m} / z+14)$, C6- and C1-oxidized oligosaccharides $(m / z+30)$, and $\mathrm{C} 1$-, $\mathrm{C} 4-$ and C6-oxidized oligosaccharides $(\mathrm{m} / z+28)$ were observed in Y27A, a minor amount of C4- and C1-oxidized oligosaccharides $(\mathrm{m} / z+14)$, C6- and C1-oxidized oligosaccharides $(\mathrm{m} / \mathrm{z}$ +30 ), and C1-, C4- and C6-oxidized oligosaccharides $(\mathrm{m} / z+28)$ were observed in H64A, a minor amount of C4- and C1-oxidized oligosaccharides $(m / z+14)$ but no C6- and C1-oxidized oligosaccharides $(\mathrm{m} / z+30)$ and C1-, C4- and C6-oxidized oligosaccharides $(\mathrm{m} / z+28)$ were observed in Y206A, and no oxidized oligosaccharides were observed in H157A (Fig. 8). Similar analysis of insoluble reaction products showed that $\mathrm{C} 4-$ and C1-oxidized oligosaccharides $(m / z+14)$ and C6- and C1-oxidized oligosaccharides $(\mathrm{m} / z+30)$ were observed in Y27A, a minor amount of C4- and C1-oxidized oligosaccharides $(m / z+14)$ were observed in H64A, and no 


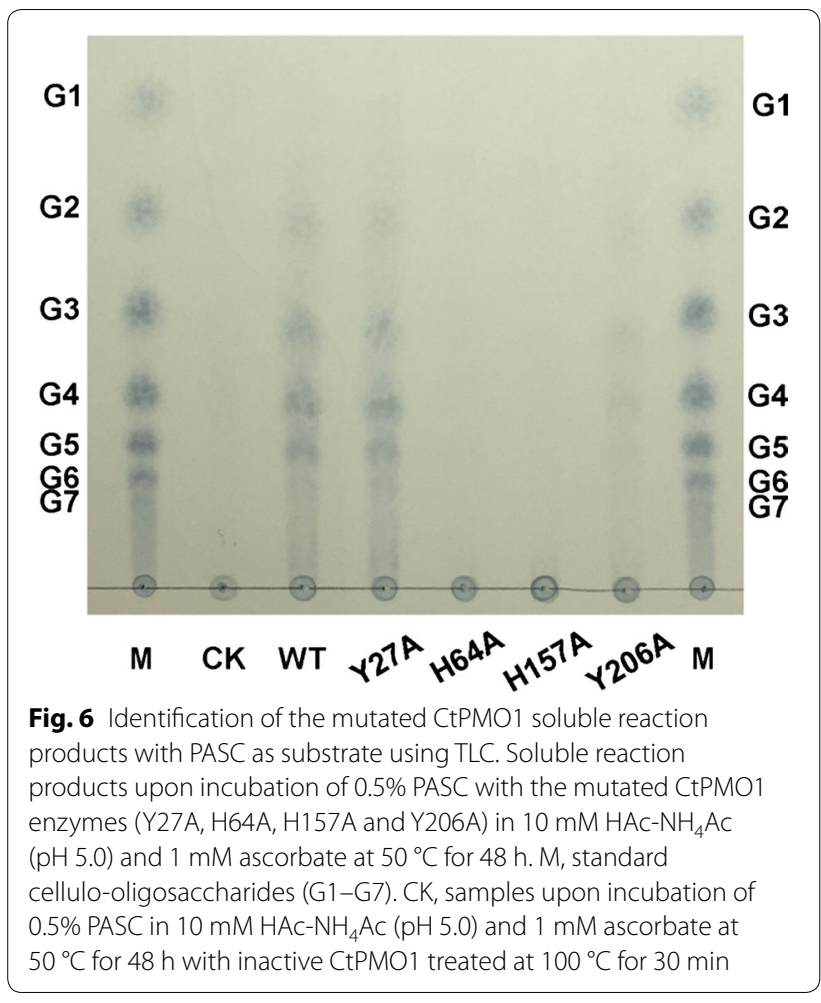

C4- and C1-oxidized oligosaccharides $(m / z+14)$ and C6- and C1-oxidized oligosaccharides $(\mathrm{m} / z+30)$ were observed in H157A and Y206A (Fig. 9).

Together, these data indicate that the mutated enzyme Y27A retained complete activity of $\mathrm{C} 1, \mathrm{C} 4$, and $\mathrm{C} 6$ oxidation on cellulose; the mutated enzyme Y206A retained partial activity of $\mathrm{C} 1$ and $\mathrm{C} 4$ oxidation but completely lost activity of $\mathrm{C} 6$ oxidation on cellulose; the mutated enzyme H64A almost completely lost activity of C1, C4, and C6 oxidation on cellulose; and the mutated enzyme H157A completely lost activity of $\mathrm{C} 1, \mathrm{C} 4$, and $\mathrm{C} 6$ oxidation on cellulose (Table 1), suggesting that the residue His157 in CtPMO1 is required for activity of $\mathrm{C} 1, \mathrm{C} 4$, and $\mathrm{C} 6$ oxidation on cellulose; the residue His64 in CtPMO1 plays a key role in retaining activity of $\mathrm{C} 1, \mathrm{C} 4$, and $\mathrm{C} 6$ oxidation on cellulose; the residue Tyr206 in CtPMO1 plays a partial role in retaining activity of $\mathrm{C} 1$ and $\mathrm{C} 4$ oxidation but a key role in retaining activity of $\mathrm{C} 6$ oxidation on cellulose; and the residue Tyr27 in CtPMO1 may not play an important role in retaining activity of $\mathrm{C} 1, \mathrm{C} 4$, and $\mathrm{C} 6$ oxidation on cellulose.

\section{Discussion}

Cello-oligosaccharides containing a C6 aldehyde can be oxidized by $\mathrm{I}_{2}$ and $\mathrm{Br}_{2}$ to the corresponding uronic acids [12]. In this study, we developed a simple and effective chemical method, using $\mathrm{Br}_{2}$ to oxidize CtPMO1 reaction products for identifying $\mathrm{C} 4$ - and C6-oxidized products. The method has three potential advantages. First, because there is no interference by metal ions $\left(\mathrm{Na}^{+}\right.$ and $\left.\mathrm{Ag}^{+}\right), \mathrm{Br}_{2}$ oxidation of CtPMO1 products allows us to directly identify C4- and C6-oxidized products using MALDI-TOF-MS analysis, but there is interference of metal ions $\left(\mathrm{Na}^{+}\right.$and $\left.\mathrm{Ag}^{+}\right)$in CtPMO1 products oxidized by $\mathrm{I}_{2}$. Second, residual $\mathrm{Br}_{2}$ in CtPMO1 products oxidized by $\mathrm{Br}_{2}$ is very easily removed under a stream of nitrogen at $40{ }^{\circ} \mathrm{C}$, unlike the removal of $\mathrm{I}_{2}$ which requires adding excess $\mathrm{Ag}_{2} \mathrm{CO}_{3}$ in CtPMO1 products oxidized by $\mathrm{I}_{2}$. Third, $\mathrm{Br}_{2}$ oxidation of CtPMO1 reaction products provided acidic conditions that can prevent the generation of unsaturated oligosaccharides, unlike oxidized by $\mathrm{I}_{2}$ under alkali conditions.

CtPMO1 oxidizes PASC to produce $\mathrm{C} 1-, \mathrm{C} 4-$, and C6-oxidized products in its soluble reaction products and C4- and C1-oxidized products in its insoluble reaction products, but C6-oxidized products are minor in its insoluble reaction products. One possible explanation for this is that C6-oxidized oligosaccharides in CtPMO1 soluble reaction products may be mainly produced by C6 oxidation of C4- and C1-cleaved soluble oligosaccharides (oxidized and nonoxidized oligosaccharides). This explanation is supported by the evidence that CtPMO1 C6-oxidizes soluble celloheptaose to produce C6-oxidized oligosaccharides and that LsAA9A and CvAA9A C4-oxidize small oligosaccharides, whereas they C4- and C1-oxidize polysaccharides [28]. Conformational flexibility of soluble cello-oligosaccharides possibly causes the changes in oxidation type $(\mathrm{C} 1, \mathrm{C} 4$, and $\mathrm{C} 6)$ of a PMO enzyme. It should be pointed out that three PMOs (TaGH61A, PaGH61B and CtPMO1) identified to oxidize C6 position of cellulose $([7,15]$, this study) have a long reaction time (TaGH61A for $22 \mathrm{~h}, \mathrm{PaGH61B}$ for $48 \mathrm{~h}$ and CtPMO1 for $48 \mathrm{~h}$ ) to produce C6-oxidized oligosaccharides. The long reaction time also hints that $\mathrm{C} 6$-oxidized oligosaccharides may be produced from C4- and/or C1-oxidize polysaccharides by PMO C6 oxidation.

It has been suggested that aromatic residues on the PMO protein flat surface are involved in substrate binding $[14,27,28]$. In this study, mutation of the residue His157 in CtPMO1 results in complete loss of activity of $\mathrm{C} 1, \mathrm{C} 4$, and $\mathrm{C} 6$ oxidation on cellulose, maybe because the residue His157 is adjacent to the copper ion-binding site of CtPMO1. Interestingly, mutation of the residue His64 in CtPMO1 results in almost complete loss of activity of $\mathrm{C} 1, \mathrm{C} 4$, and $\mathrm{C} 6$ oxidation on cellulose. The residue His64 lies in a sequence insertion (L3 loop) that seems unique for C4-oxidizing PMOs [27]. It has been reported that an additional metal-binding site (copper or zinc ion) is coordinated by the residue His64 in NcLPMO9C from N. crass [27]. Recent studies 


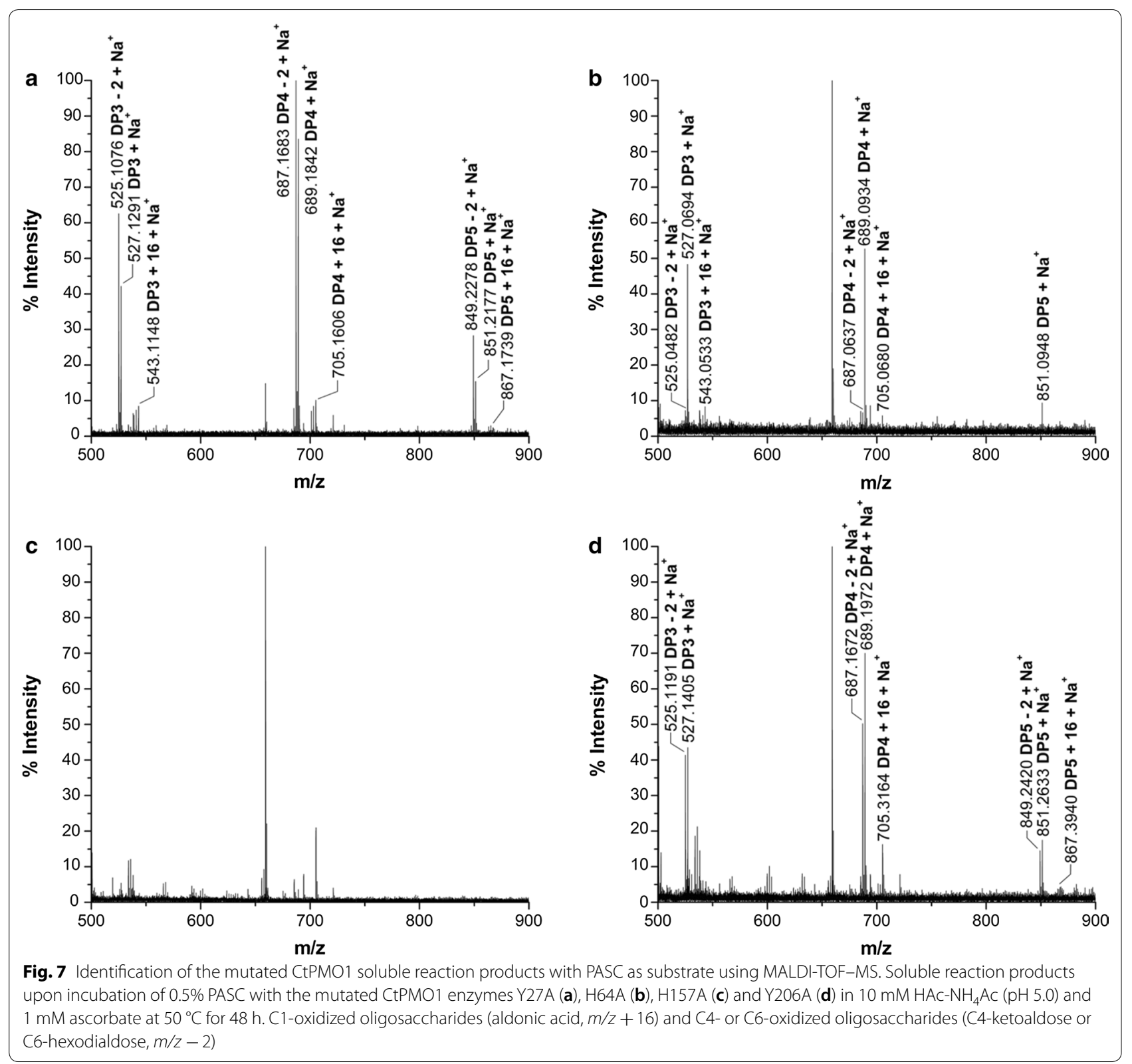

of LsAA9A-substrate interaction show that a hydrogen bond is present between the residue His66 in LsAA9A (His64 in CtPMO1 and NcLPMO9C) and O3 at substrate +2 [28]. These data suggest that the residue His (His64 in CtPMO1 and NcLPMO9C, His66 in LsAA9A) plays a role in PMO-substrate interaction. Mutation of the residue Tyr206 in CtPMO1 results in partial loss of activity of $\mathrm{C} 1$ and $\mathrm{C} 4$ oxidation and complete loss of C6 oxidation on cellulose, may be because the residue Tyr206 is far away from the copper ion-binding site (at subsite

(See figure on next page.)

Fig. 8 Identification of the mutated CtPMO1 soluble reaction products oxidized by $\mathrm{Br}_{2}$ with PASC as substrate using MALDI-TOF-MS. Soluble reaction products upon incubation of $0.5 \%$ PASC with the mutated CtPMO1 enzymes Y27A (a), H64A (b), H157A (c) and Y206A (d) in $10 \mathrm{mM}$ HAc-NH 4 Ac ( $\mathrm{pH} \mathrm{5.0)}$ and $1 \mathrm{mM}$ ascorbate at $50^{\circ} \mathrm{C}$ for $48 \mathrm{~h}$. C1-oxidized oligosaccharides $(\mathrm{m} / \mathrm{z}+16), \mathrm{C} 4$-oxidized oligosaccharides $(\mathrm{m} / \mathrm{z}+14)$, C6-oxidized oligosaccharides $(m / z+30)$, and C6- and C4-oxidized oligosaccharides $(m / z+28)$ 


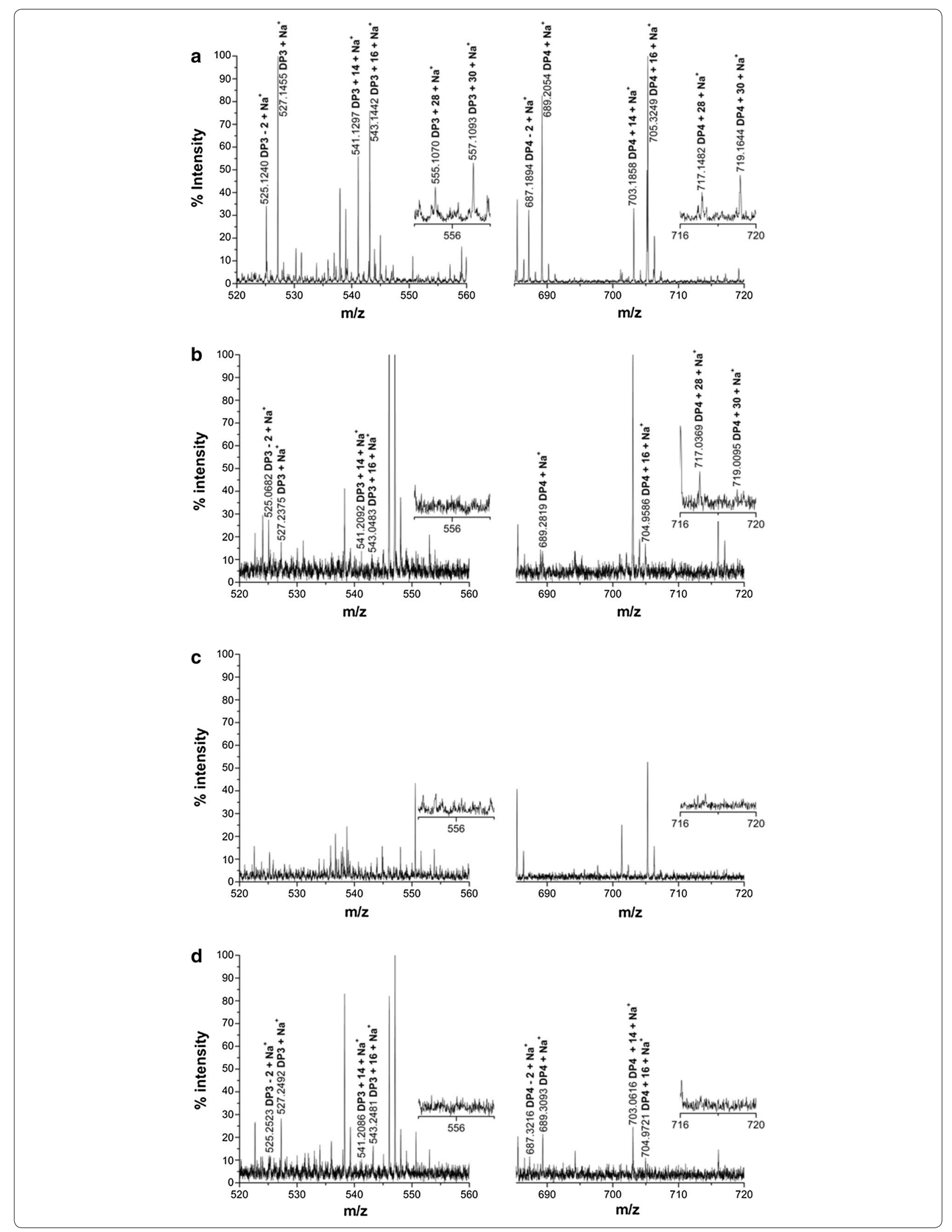




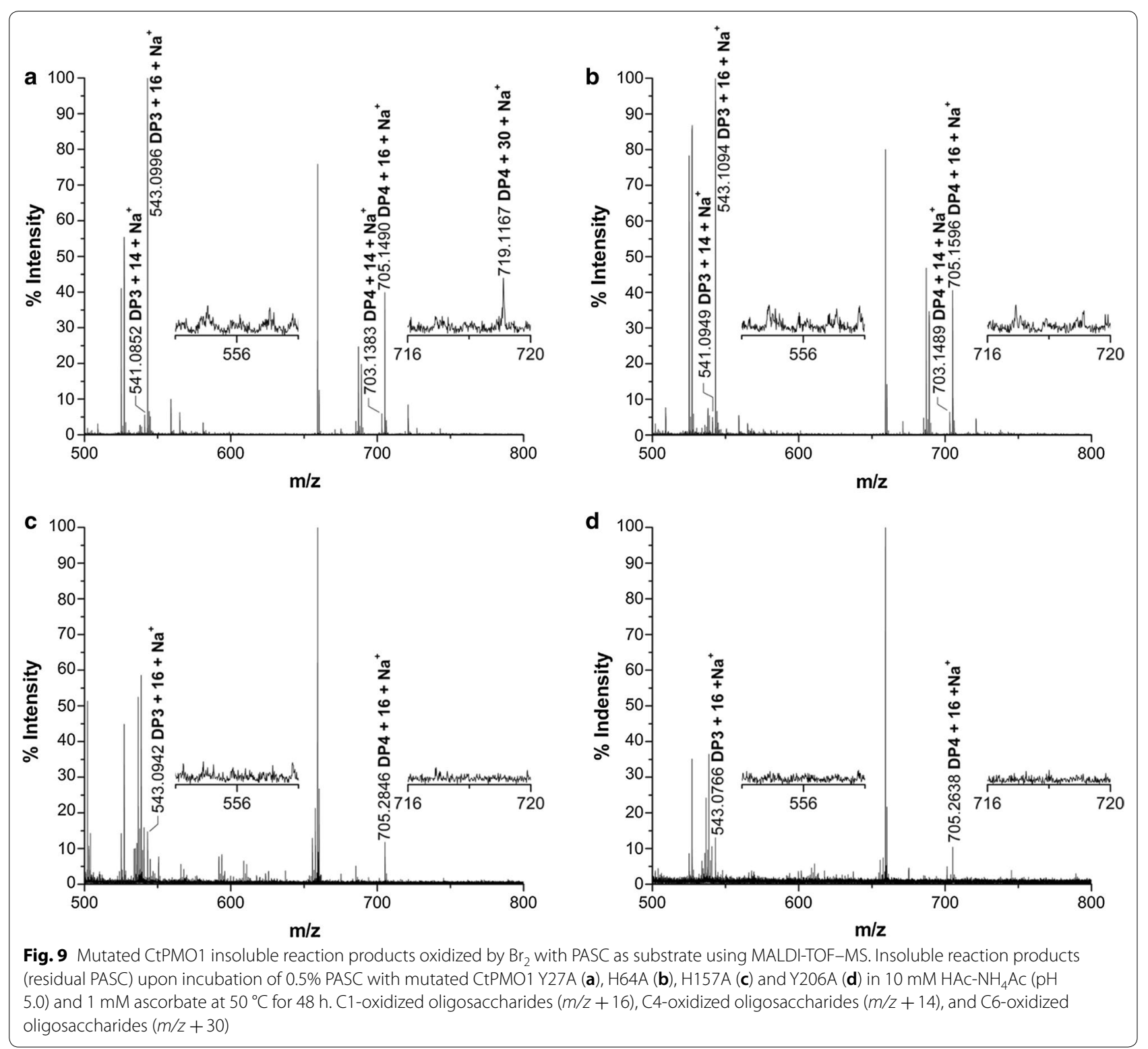

Table 1 Composition of CtPMO1 and its mutants' reaction products with PASC as substrate

\begin{tabular}{|c|c|c|c|c|c|c|c|c|}
\hline \multirow[t]{2}{*}{ Enzyme } & \multicolumn{4}{|c|}{ Soluble reaction products } & \multicolumn{4}{|c|}{ Insoluble reaction products } \\
\hline & $\mathrm{C} 1$ & $\mathrm{C} 4$ & $\mathrm{C} 6$ & $\mathrm{C} 4+\mathrm{C} 6$ & $\mathrm{C} 1$ & $\mathrm{C} 4$ & $\mathrm{C} 6$ & $\mathrm{C} 4+\mathrm{C} 6$ \\
\hline WT & +++ & +++ & +++ & +++ & +++ & +++ & + & - \\
\hline Y27A & +++ & +++ & +++ & +++ & +++ & +++ & + & - \\
\hline $\mathrm{H} 64 \mathrm{~A}$ & + & + & + & + & + & + & - & - \\
\hline H157A & - & - & - & - & - & - & - & - \\
\hline Y206A & + & + & - & - & + & - & - & - \\
\hline
\end{tabular}

"+++": products can be detected; "+": minor products can be detected; "-": no products 
$-3)$, suggesting that it may function as a carbohydratebinding module to enhance binding affinity. The evidence that stacking of Tyr203 in LsAA9A (Tyr206 in CtPMO1) is a major interaction in LsAA9A:Cell5 supports this suggestion [28]. Mutation of the residue Tyr27 in CtPMO1 results in no loss of activity of $\mathrm{C} 1, \mathrm{C} 4$, and $\mathrm{C} 6$ oxidation on cellulose, perhaps because the residue Tyr27 is far away from the copper ion-binding site. Because of the absence of structural data of the residue Tyr27, whether it plays a role in CtPMO1-substrate interaction needs be further studied in the future.

It has been suggested that there are different modes for substrate binding by PMOs, inter-chain binding modes and intra-chain binding modes, which allow the active site of PMOs to be close to hydrogen of $\mathrm{C} 1, \mathrm{C} 4$, and $\mathrm{C} 6$ carbon of cellulose [14]. Recent studies of PMO-substrate interaction show that the active site of LsAA9A from Lentinus similis is close to hydrogen of C1, C4, and C6 carbon of the soluble Cell5 substrate [28]. These structural data support $\mathrm{C} 1, \mathrm{C} 4$, and $\mathrm{C} 6$ oxidation of PMOs on cellulose and cello-oligosaccharides.

It is unclear how CtPMO1 oxidizes C6 carbon of cellooligosaccharides. To our knowledge, only galactose oxidase (EC 1.1.3.9) is a single C6-oxidizing copper metalloenzyme that catalyses $\mathrm{C} 6$ oxidation of galactose and its derivatives $[4,26,29]$. Although the overall sequence similarity is low between galactose oxidase and PMO, the two enzymes have very similar active sites. Four highly conserved amino acid side chains (from Tyr272, Tyr495, His496, and His581) directly coordinate copper in a galactose oxidase and the residue Tyr495 is buried and lies in the protein-facing axial position with a distance of $2.6 \AA$ from the copper to the oxygen atom of the Tyr459 side chain [29], similar to the highly conserved and buried residue Tyr168 within CtPMO1.

C6 oxidation of PMOs is interesting because, unlike $\mathrm{C} 1$ and $\mathrm{C} 4$ oxidation, it cannot directly cleave the glycosidic bond of cellulose. CtPMO1 C6-oxidizes soluble oligosaccharides to produce C6-oxidized oligosaccharides (C6-hexodialdose). It is possible that an unknown mechanism (e.g., a secreted oxidoreductase) might further oxidize C6-hexodialdose generated by PMOs to form glucuronic acid-containing cello-oligosaccharides as $\mathrm{I}_{2}$ oxidizes C6-hexodialdose. We hypothesize that there may be two possible enzymatic reactions to degrade glucuronic acid-containing cello-oligosaccharides. One is betaelimination by polysaccharide lyase. It is well known that polysaccharide lyase family 20 endo-beta-1,4-glucuronan lyases can cleave the glycosidic bond of a glucuronic acidcontaining cello-oligosaccharide via beta-elimination [30-32]. The other is hydrolysed by $\beta$-glucuronidase and $\beta$-glucosidase. The two enzymes can alternately hydrolyze glucuronic acid-containing cello-oligosaccharides to yield glucuronic acid [33, 34]. As an important organic acid, glucuronic acid may act as a chelate required for manganese peroxidase to stimulate its activity by stabilizing $\mathrm{Mn}^{3+}$ for depolymerization of lignin [35], or it may be metabolized by the uronic acid pathway in cells to produce important active substances, such as ascorbate $(\mathrm{Vc})$ and D-xylulose [32, 36].

Fungal oxidative degradation of cellulose is complex in nature. Recent genomic sequencing shows multigenicity of AA9 genes in fungi [4]. One of the most extreme examples is that Coprinopsis cinerea contains 33 putative AA9 genes [37]. Two thermophilic fungi Thielavia terrestris and Myceliophthora thermophila contain 24 and 20 putative AA9 genes, respectively [38]. The thermophilic fungus $C$. thermophilum contains 19 putative AA9 genes (http://www.fungalgenomics.cn). These data suggest that AA9 proteins have diverse functions, including regioselectivity diversity.

\section{Conclusions}

CtPMO1 was successfully expressed and correctly processed in P. pastoris. A simple and effective chemical method to directly identify C4- and C6-oxidized products by $\mathrm{Br}_{2}$ oxidation. CtPMO1 can cleave PASC and celloheptaose, and product identification shows that it also can oxidize three carbon positions in PASC and cellooligosaccharides so belonging to a C1-, C4- and C6-oxidizing PMO. The mutants of CtPMO1 demonstrated that Y27A retained complete activity of $\mathrm{C} 1, \mathrm{C} 4, \mathrm{C} 6$ oxidation, indicating Tyr27 effects little to activity of $\mathrm{C} 1, \mathrm{C} 4$, C6 oxidation; Y206A retained partial activity of $\mathrm{C} 1$ and C4 oxidation but completely lost activity of C6 oxidation, indicating that Tyr206 mainly affects activity of $\mathrm{C} 6$ oxidation with partial impact on activity of $\mathrm{C} 1$ and $\mathrm{C} 4$ oxidation; H64A almost completely lost activity of C1, C4, C6 oxidation, indicating His64's importance in $\mathrm{C} 1, \mathrm{C} 4, \mathrm{C} 6$ oxidation; H157 A completely lost activity of C1, C4, C6 oxidation, indicating that His157 has a crucial role in the overall activity of CtPMO1.

\section{Methods}

Strains, plasmids, culture media, and chemicals Chaetomium thermophilum CGMCC3.17990 strain was previously isolated in China and deposited in the publicly accessible culture collection CGMCC (Beijing, China). We purchased the plasmid vector $\mathrm{pPICZ} \alpha \mathrm{A}$ and Pichia pastoris GS115 strain from Invitrogen. For total RNA isolation, we grew C. thermophilum at $50{ }^{\circ} \mathrm{C}$ for $48 \mathrm{~h}$ in 
a medium containing $2 \%$ avicel, $0.4 \%$ yeast extract, $0.1 \%$ $\mathrm{K}_{2} \mathrm{HPO}_{4} \cdot 3 \mathrm{H}_{2} \mathrm{O}$, and $0.05 \% \mathrm{MgSO}_{4} \cdot 7 \mathrm{H}_{2} \mathrm{O}$, dissolved in tap water. Avicel PH-101, glucose, gluconic acid, and ascorbate were from Sigma-Aldrich. Cellodextrin oligosaccharide mixture and cellopentaose were from Elicityl (Crolles, France). Other reagents were of analytic grade.

\section{Molecular cloning of CDNA}

We used Trizol reagent (Gibco) for total RNA isolation of $C$. thermophilum from mycelia. We performed RTPCR with RNA PCR Kit 3.0 instruction (Takara). We used PCR to amplify the cDNA of the CtPMO1 protein, termed Ctpmo1, with a pair of specific oligonucleotide primers (CtPMO1-cF/CtPMO1-cR) synthesized based on the gene (KC441882) from the genomic sequencing of $C$. thermophilum (Additional file 1: Table S1).

\section{Construction of Ctpmo1 expression vector}

We used PCR to amplify the Ctpmo1 fragment of the coding region without a signal peptide sequence with a pair of specific primer (CtPMO1-F/CtPMO1-R), which contained an $\mathrm{XhoI}$ and an $\mathrm{XbaI}$ restriction site, respectively (Additional file 1 : Table $\mathrm{S} 1$ ). The PCR product was digested with $X h o I$ and $X b a I$ and ligated with pPICZ $\alpha A$, yielding the expression plasmid pPICZ $\alpha \mathrm{A} / C t p m o 1$, which ensured the expression of CtPMO1 in P. pastoris with a native $\mathrm{N}$-terminus (Invitrogen). Through DNA sequencing, we confirmed that the constructed recombinant plasmid pPICZ $\alpha \mathrm{A} / \mathrm{Ctpmo1}$ contained the Ctpmo1 sequence.

\section{Transformation of $P$. pastoris}

After linearized with $S a c \mathrm{I}$, we transformed the recombinant plasmid pPICZ $\alpha \mathrm{A} / \mathrm{Ctpmo1}$ to P. pastoris GS115 by electroporation with BTX ECM830 Electroporator (Harvard Apparatus). We selected the transformants on YPDS plates containing $100 \mathrm{mg} / \mathrm{L}$ zeocin and verified them with PCR amplifications and DNA sequencing (Invitrogen).

\section{CtPMO1 induction and purification}

We induced the CtPMO1 protein in transformed $P$. pastoris with the Pichia Expression System Kit (Invitrogen). The transformed $P$. pastoris was cultured at $28{ }^{\circ} \mathrm{C}$ for 6 days in a shake flask in BMMY medium containing $1 \mathrm{mM} \mathrm{Cu}^{2+}$. We centrifuged $1000 \mathrm{~mL}$ of the culture filtrate at $10,000 \mathrm{~g}$ at $4{ }^{\circ} \mathrm{C}$ for $15 \mathrm{~min}$. To the supernatant, we added $\left(\mathrm{NH}_{4}\right)_{2} \mathrm{SO}_{4}$ to $90 \%$ saturation and gently stirred and kept the solution for $12 \mathrm{~h}$ at $4{ }^{\circ} \mathrm{C}$. We collected the resulting precipitate by centrifuging it at $10,000 \mathrm{~g}$ at $4{ }^{\circ} \mathrm{C}$ for $15 \mathrm{~min}$, then dissolved it in $50 \mathrm{mM}$ phosphate buffered saline buffer ( $\mathrm{pH}$ 7.4), and dialyzed it overnight at $4{ }^{\circ} \mathrm{C}$ against at least three changes of the same buffer. We purified the C-terminal histidine-tagged CtPMO1 protein through affinity chromatography on a His Trap column (GE Healthcare) with the following steps: balanced His Trap column with buffer A $(300 \mathrm{mM} \mathrm{NaCl}$, $2.7 \mathrm{mM} \mathrm{KCl}, 10 \mathrm{mM} \mathrm{K} \mathrm{HPO}_{4}, 2 \mathrm{mM} \mathrm{KH} \mathrm{PO}_{4}, 10 \mathrm{mM}$ imidazole, $\mathrm{pH}$ 7.4), then loaded the crude enzyme followed by rebalancing the column with buffer $\mathrm{B}(300 \mathrm{mM}$ $\mathrm{NaCl}, 2.7 \mathrm{mM} \mathrm{KCl}, 10 \mathrm{mM} \mathrm{K}{ }_{2} \mathrm{HPO}_{4}, 2 \mathrm{mM} \mathrm{KH_{2 }} \mathrm{PO}_{4}$, $30 \mathrm{mM}$ imidazole, $\mathrm{pH}$ 7.4), and eluted CtPMO1 protein by buffer $\mathrm{C}\left(300 \mathrm{mM} \mathrm{NaCl}, 2.7 \mathrm{mM} \mathrm{KCl}, 10 \mathrm{mM} \mathrm{K}_{2} \mathrm{HPO}_{4}\right.$, $2 \mathrm{mM} \mathrm{KH}_{2} \mathrm{PO}_{4}, 250 \mathrm{mM}$ imidazole, $\mathrm{pH}$ 7.4). The purified protein was pooled and dialyzed fractions overnight at $4{ }^{\circ} \mathrm{C}$ against three changes of $10 \mathrm{mM} \mathrm{HAc}-\mathrm{NH}_{4} \mathrm{Ac}$ buffer (pH 5.0). We used the purified and desalted $\mathrm{Cu}^{2+}$-loaded CtPMO1 protein for further functional studies.

\section{Protein determination and SDS-PAGE}

We used the Lowry method for protein determination [39], determining the purity of the CtPMO1 protein using SDS-PAGE [40].

\section{The N-terminal amino acid sequence analysis of CtPMO1 protein}

We applied LC-MS/MS to determine the N-terminal amino acid sequence of CtPMO1. We performed ingel tryptic digestion of the purified CtPMO1 with the method previously described [41], extracting and analyzing the resulting peptides with a nano-LC combined with Q Exactive mass spectrometer (Thermo Scientific) in the positive ion mode [42]. We acquired MS and MS/MS spectra on the mass range of $\mathrm{m} / \mathrm{z}$ range of $300-1800$ and $100-1000$, respectively. We analyzed all data using MASCOT 2.2 software (Matrix Science) and searched MS/MS spectra against the CtPMO1 protein sequence database.

\section{Activity assay}

We used PASC as substrate, prepared from Avicel according to the method previously described [7]. Assays contained $5 \mathrm{mg} / \mathrm{mL}$ (0.5\%) PASC or $1 \mathrm{mg} / \mathrm{mL}(0.1 \%)$ cellopentaose and $5 \mu \mathrm{M} \mathrm{Cu}^{2+}$-loaded CtPMO1 protein in $10 \mathrm{mM} \mathrm{HAc}-\mathrm{NH}_{4} \mathrm{Ac}(\mathrm{pH} 5.0)$ and $1 \mathrm{mM}$ ascorbate for $48 \mathrm{~h}$ at $50{ }^{\circ} \mathrm{C}$. When PASC used as substrate, the reaction mixture was centrifuged at $10,000 \mathrm{~g}$ at $4{ }^{\circ} \mathrm{C}$ for $10 \mathrm{~min}$. The supernatant was recovered for analysis of soluble reaction products of CtPMO1. The precipitate (residual PASC) was washed with water three times and was finally suspended in $10 \mathrm{mM} \mathrm{HAc}-\mathrm{NH}_{4} \mathrm{Ac}$ (pH 5.0). To release oxidized oligosaccharides from insoluble reaction products of CtPMO1, the residual PASC was hydrolyzed with endo-1,4-beta-glucanase from Acidothermus cellulolyticus (Sigma) at $50{ }^{\circ} \mathrm{C}$ for $10 \mathrm{~min}$, centrifuged at $10,000 \mathrm{~g}$ at $4{ }^{\circ} \mathrm{C}$ for $10 \mathrm{~min}$, and the supernatant was recovered for analysis of insoluble reaction products of CtPMO1. 
TLC

We applied TLC to analyze CtPMO1 products, applying samples to TLC on a Silica gel 60 F254 (Merck). We developed the plates using ethyl acetate:methanol:acetic acid:water (4:2:0.25:1, v/v) and visualized CtPMO1 products by heating them at $85^{\circ} \mathrm{C}$ for $30 \mathrm{~min}$ with the chromogenic agent, which contained $4 \mathrm{~mL}$ phenylamine, $4 \mathrm{~g}$ diphenylamine, $30 \mathrm{~mL} \mathrm{85 \%} \mathrm{(w/w)} \mathrm{phosphoric} \mathrm{acid,} \mathrm{and}$ $200 \mathrm{~mL}$ acetone. Cellodextrin oligosaccharide mixture was used as markers.

\section{MALDI-TOF MS and MALDI-TOF MS/MS}

We analyzed CtPMO1 using MALDI-TOF MS/MS. We applied samples to MALDI-TOF MS/MS on a 5800 MALDI-TOF/TOF analyzer (AB SCIEX) and analyzed them as described previously [6]. For MALDI-TOF MS measurements, we used an ionic preparation of 5-chloro2-mecapto-benzothiazole (CMBT) and 2, 5-dihydroxybenzoic acid (DHB) as the matrix. $2 \mu \mathrm{L}$ of the mixture of the samples and the matrix in a $1: 1$ ratio $(\mathrm{v} / \mathrm{v})$ was deposited on a target plate. The mass spectrometer was operated in the positive ion mode. MS data acquisition mass range was from $m / z 500$ to 1100 . MS/MS data were acquired on the mass range of $\mathrm{m} / z$ range of $10-550$. Fragmentation ion types were nominated as previously described [43].

\section{Analysis of CtPMO1 products oxidized by $\mathrm{Br}_{2}$}

We used saturated bromine water (approximately 3\%, w/v) to oxidize CtPMO1 products at $60{ }^{\circ} \mathrm{C}$ for 30 or $60 \mathrm{~min}$ and dried under a stream of nitrogen at $40{ }^{\circ} \mathrm{C}$. Dried samples were then dissolved in water for MALDITOF MS analysis.

\section{NMR spectroscopy}

CtPMO1 products were dissolved in DMSO- $d_{6}$ solution and analyzed by NMR spectroscopy. NMR spectra were recorded at $25^{\circ} \mathrm{C}$ on an Avance III $400 \mathrm{MHz}$ instrument (Bruker), using TMS $(\delta=0.00)$ as internal reference. One-dimensional spectra were acquired and processed using standard MestReNova software (Bruker).

\section{Site-directed mutagenesis}

Site-directed mutagenesis of CtPMO1 was carried out according to the QuickChangeTM Site-Directed mutagenesis Kit (Stratagene, USA). The sequences of the primers used for CtPMO1 site-directed mutagenesis are shown in Additional file 1: Table S1. The PCR for mutation was performed with the following amplification program: 1 cycle at $95{ }^{\circ} \mathrm{C}$ for $2 \mathrm{~min}, 20$ cycles composed of three steps for each cycle $\left(95^{\circ} \mathrm{C}\right.$ for $20 \mathrm{~s}, 55^{\circ} \mathrm{C}$ for $20 \mathrm{~s}$, $72{ }^{\circ} \mathrm{C}$ for $2 \mathrm{~min}$ ) followed by a final elongation step at $72{ }^{\circ} \mathrm{C}$ for $5 \mathrm{~min}$. The mutated proteins were expressed and purified as the wild-type CtPMO1 protein.

\section{Homology modeling}

Homology modeling of CtPMO1 was carried out using Swiss-Model server (http://www.swissmodel.expasy.org).

\section{Additional file}

Additional file 1: Figure S1. SDS-PAGE of the purified $\mathrm{Cu}^{2+}-\mathrm{CtPMO} 1$ produced in Pichia pastoris. Figure S2. The N-terminal amino acid sequence analysis of CtPMO1 using LC-MS/MS. Figure S3. MALDI-TOFMS/MS analysis of $m / z 525$ from MALDI-TOF-MS analysis. Figure S4. Types of fragmentation of CtPMO1 C4- and C6-oxidized products (m/z 525). Figure S5. ${ }^{1} \mathrm{H}$ NMR spetra of CtPMO1 soluble reaction products with PASC as substrate in DMSO- $d_{6}$. Figure $\mathbf{S 6}$. Sequence alignment of CtPMO1 and NCLPMO9C using ClastalW2. Figure S7. Homology model of the catalytic domain of CtPMO1 using SWISS-MODEL. Figure S8. Homology model of CtPMO1 binding with cellopentaose. Figure S9. Identification of the mutated $\mathrm{CtPMO} 1$ soluble reaction products oxidized by $\mathrm{Br}_{2}$ using with PASC as substrate MALDI-TOF-MS. Table S1. List of primers used for PCR of the CtPMO1 protein. Table S2. Fragmentation analysis of the peak of $\mathrm{DP}_{3}-2$ (m/z 525) according to Additional file 1: Figure S3, S4.

\section{Abbreviations}

PMOs: polysaccharide monooxygenases; CtPMO1: a PMO from Chaetomium thermophilum; PASC: phosphoric acid-swollen cellulose; TFA: trifluoroacetic acid; AA: auxiliary activity; PCR: polymerase chain reaction; SDS-PAGE: sodium dodecyl sulfate polyacrylamide gel electrophoresis; LC-MS/MS: liquid chromatograph-tandem mass spectrometry; TLC: thin-layer chromatography; HPAEC-PAD: high-performance anion exchange chromatography with pulsed amperometric detection; DP: degree of polymerization; MALDI-TOF-MS/ MS: matrix-assisted laser desorption/ionization-time-of-flight tandem mass spectrometry; LC-MS: liquid chromatograph-mass spectrometry; NMR: nuclear magnetic resonance; G1: glucose; G2: cellobiose; G3: cellotriose; G4: cellotetraose; G5: cellopentaose; G6: cellohexose; G7: celloheptaose; TMS: tetramethyl silane.

\section{Authors' contributions}

DCL and CC designed the study and wrote the paper. CC, JYC, ZGG, MXW and $\mathrm{NL}$ performed and analyzed experiments. CC contributed to the preparation of the figures and tables. All authors reviewed the results. All authors read and approved the final manuscript.

\section{Acknowledgements}

Not applicable.

Competing interests

The authors declare that they have no competing interests.

Consent for publication

Not applicable.

Ethics approval and consent to participate

Not applicable.

\section{Funding}

This work was supported by the Chinese National Key Technology Support Program (2015BAD15B05), the Chinese National Nature Science Foundation (31571949) and the Chinese National Programs for High Technology, Research, and Development (2012AA10180402). 


\section{Publisher's Note}

Springer Nature remains neutral with regard to jurisdictional claims in published maps and institutional affiliations.

Received: 25 April 2018 Accepted: 29 May 2018 Published online: 05 June 2018

\section{References}

1. Wilson DB. Cellulases and biofuels. Curr Opin Biotechnol. 2009;20:295-9.

2. Percival Zhang YH, Himmel ME, Mielenz JR. Outlook for cellulase improvement: screening and selection strategies. Biotechnol Adv. 2006;24:452-81.

3. Service RF. Is there a road ahead for cellulosic ethanol? Science. 2010;329:784-5.

4. Levasseur A, Drula E, Lombard V, Coutinho PM, Henrissat B. Expansion of the enzymatic repertoire of the CAZy database to integrate auxiliary redox enzymes. Biotechnol Biofuels. 2013;6:41.

5. Harris PV, Welner D, MCFarland KC, Re E, Navarro Poulsen JC, Brown K, Salbo R, Ding H, Vlasenko E, Merino S, Xu F, Cherry J, Larsen S, Lo Leggio L. Stimulation of lignocellulosic biomass hydrolysis by proteins of glycoside hydrolase family 61: structure and function of a large, enigmatic family. Biochemistry. 2010;49:3305-16.

6. Vaaje-Kolstad G, Westereng B, Horn SJ, Liu Z, Zhai H, Sorlie M, Eijsink VG. An oxidative enzyme boosting the enzymatic conversion of recalcitrant polysaccharides. Science. 2010;330:219-22.

7. Quinlan RJ, Sweeney MD, Lo Leggio L, Otten H, Poulsen JC, Johansen KS, Krogh KB, Jorgensen Cl, Tovborg M, Anthonsen A, Tryfona T, Walter CP, Dupree $\mathrm{P}, \mathrm{Xu}$ F, Davies GJ, Walton PH. Insights into the oxidative degradation of cellulose by a copper metalloenzyme that exploits biomass components. Proc Natl Acad Sci USA. 2011:108:15079-84.

8. Aachmann FL, Sorlie M, Skjak-Braek G, Eijsink VG, Vaaje-Kolstad G. NMR structure of a lytic polysaccharide monooxygenase provides insight into copper binding, protein dynamics, and substrate interactions. Proc Natl Acad Sci USA. 2012;109:18779-84.

9. Hemsworth GR, Henrissat B, Davies GJ, Walton PH. Discovery and characterization of a new family of lytic polysaccharide monooxygenases. Nat Chem Biol. 2014;10:122-6.

10. Lo Leggio L, Simmons TJ, Poulsen JN, Frandsen KEH, Hemsworth GR, Stringer MA, von Freiesleben P, Tovborg M, Johansen KS, De Maria L, Harris PV, Soong CL, Dupree P, Tryfona T, Lenfant N, Henrissat B, Davies GJ, Walton PH. Structure and boosting activity of a starch-degrading lytic polysaccharide monooxygenase. Nat Commun. 2015;6:5961.

11. Phillips CM, Beeson WT, Cate JH, Marletta MA. Cellobiose dehydrogenase and a copper-dependent polysaccharide monooxygenase potentiate cellulose degradation by Neurospora crassa. ACS Chem Biol. 2011;6:1399-406.

12. Beeson WT, Phillips CM, Cate JH, Marletta MA. Oxidative cleavage of cellulose by fungal copper-dependent polysaccharide monooxygenases. J Am Chem Soc. 2012;134:890-2.

13. Kittl R, Kracher D, Burgstaller D, Haltrich D, Ludwig R. Production of four Neurospora crassa lytic polysaccharide monooxygenases in Pichia pastoris monitored by a fluorimetric assay. Biotechnol Biofuels. 2012;5:79.

14. Li X, Beeson WT, Phillips CM, Marletta MA, Cate JH. Structural basis for substrate targeting and catalysis by fungal polysaccharide monooxygenases. Structure. 2012;20:1051-61.

15. Bey M, Zhou S, Poidevin L, Henrissat B, Coutinho PM, Berrin JG, Sigoillot JC. Cello-oligosaccharide oxidation reveals differences between two lytic polysaccharide monooxygenases (family GH61) from Podospora anserina. Appl Environ Microbiol. 2013;79:488-96.

16. Wu M, Beckham GT, Larsson AM, Ishida T, Kim S, Payne CM, Himmel ME, Crowley MF, Horn SJ, Westereng B, Igarashi K, Samejima M, Stahlberg J, Eijsink VG, Sandgren M. Crystal structure and computational characterization of the lytic polysaccharide monooxygenase GH61D from the Basidiomycota fungus Phanerochaete chrysosporium. J Biol Chem. 2013:288:12828-39.

17. Vu W, Beeson WT, Phillips CM, Cate JH, Marletta MA. Determinants of regioselective hydroxylation in the fungal polysaccharide monooxygenases. J Am Chem Soc. 2014;136:562-5.
18. Patel I, Kracher D, Ma S, Garajova S, Haon M, Faulds CB, Berrin JG, Ludwig $\mathrm{R}$, Record E. Salt-responsive lytic polysaccharide monooxygenases from the mangrove fungus Pestalotiopsis sp. NCi6. Biotechnol Biofuels. 2016;9:108.

19. Karkehabadi S, Hansson H, Kim S, Piens K, Mitchinson C, Sandgren M. The first structure of a glycoside hydrolase family 61 member, Cel61B from Hypocrea jecorina, at 1.6 A resolution. J Mol Biol. 2008;383:144-54.

20. Horn SJ, Vaaje-Kolstad G, Westereng B, Eijsink VG. Novel enzymes for the degradation of cellulose. Biotechnol Biofuels. 2012;5:45.

21. Isaksen T, Westereng B, Aachmann FL, Agger JW, Kracher D, Kittl R, Ludwig R, Haltrich D, Eijsink VG, Horn SJ. A C4-oxidizing lytic polysaccharide monooxygenase cleaving both cellulose and cello-oligosaccharides. J Biol Chem. 2014;289:2632-42.

22. Bennati-Granier C, Garajova S, Champion C, Grisel S, Haon M, Zhou S, Fanuel M, Ropartz D, Rogniaux H, Gimbert I, Record E, Berrin JG. Substrate specificity and regioselectivity of fungal AA9 lytic polysaccharide monooxygenases secreted by Podospora anserina. Biotechnol Biofuels. 2015;8:90.

23. Li AN, Yu K, Liu HQ, Zhang J, Li H, Li DC. Two novel thermostable chitinase genes from thermophilic fungi: cloning, expression and characterization. Bioresour Technol. 2010;101:5546-51.

24. Amlacher $S$, Sarges P, Flemming D, van Noort V, Kunze R, Devos DP, Arumugam M, Bork P, Hurt E. Insight into structure and assembly of the nuclear pore complex by utilizing the genome of a eukaryotic thermophile. Cell. 2011;146:277-89.

25. Tan TC, Kracher D, Gandini R, Sygmund C, Kittl R, Haltrich D, Hallberg BM, Ludwig R, Divne C. Structural basis for cellobiose dehydrogenase action during oxidative cellulose degradation. Nat Commun. 2015;6:7542.

26. Parikka K, Tenkanen M. Oxidation of methyl alpha-D-galactopyranoside by galactose oxidase: products formed and optimization of reaction conditions for production of aldehyde. Carbohydr Res. 2009;344:14-20.

27. Borisova AS, Isaksen T, Dimarogona M, Kognole AA, Mathiesen G, Varnal A, Rohr AK, Payne CM, Sorlie M, Sandgren M, Eijsink VG. Structural and functional characterization of a lytic polysaccharide monooxygenase with broad substrate specificity. J Biol Chem. 2015;290:22955-69.

28. Simmons TJ, Frandsen KEH, Ciano L, Tryfona T, Lenfant N, Poulsen JC, Wilson LFL, Tandrup T, Tovborg M, Schnorr K, Johansen KS, Henrissat B, Walton PH, Lo Leggio L, Dupree P. Structural and electronic determinants of lytic polysaccharide monooxygenase reactivity on polysaccharide substrates. Nat Commun. 2017:8:1064.

29. Whittaker JW. Free Radical catalysis by galactose oxidase. Chem Rev. 2003;103:2347-63.

30. Konno N, Ishida T, Igarashi K, Fushinobu S, Habu N, Samejima M, Isogai A. Crystal structure of polysaccharide lyase family 20 endo-beta-1,4-glucuronan lyase from the filamentous fungus Trichoderma reesei. FEBS Lett. 2009;583:1323-6.

31. Garron ML, Cygler M. Structural and mechanistic classification of uronic acid-containing polysaccharide lyases. Glycobiology. 2010;20:1547-73.

32. Elboutachfaiti R, Delattre C, Petit E, Michaud P. Polyglucuronic acids: structures, functions and degrading enzymes. Carbohydr Polym. 2011;84:1-13.

33. Leah R, Kigel J, Svendsen I, Mundy J. Biochemical and molecular characterization of a barley seed beta-glucosidase. J Biol Chem. 1995:270:15789-97.

34. Jain S, Drendel WB, Chen ZW, Mathews FS, Sly WS, Grubb JH. Structure of human beta-glucuronidase reveals candidate lysosomal targeting and active-site motifs. Nat Struct Biol. 1996;3:375-81.

35. Kersten $P$, Cullen D. Extracellular oxidative systems of the lignin-degrading Basidiomycete Phanerochaete chrysosporium. Fungal Genet Biol. 2007:44:77-87

36. Tavernier ML, Delattre C, Petit E, Michaud P. $\beta$ - $(1,4)$-Polyglucuronic acidsan overview. Open Biotechnol J. 2008;2:73-86.

37. Eastwood DC, Floudas D, Binder M, Majcherczyk A, Schneider P, Aerts A, Asiegbu FO, Baker SE, Barry K, Bendiksby M, Blumentritt M, Coutinho PM, Cullen D, de Vries RP, Gathman A, Goodell B, Henrissat B, Ihrmark K, Kauserud H, Kohler A, LaButti K, Lapidus A, Lavin JL, Lee YH, Lindquist E, Lilly W, Lucas S, Morin E, Murat C, Oguiza JA, Park J, Pisabarro AG, Riley R, Rosling A, Salamov A, Schmidt O, Schmutz J, Skrede I, Stenlid J, Wiebenga A, Xie X, Kues U, Hibbett DS, Hoffmeister D, Hogberg N, Martin F, Grigoriev IV, Watkinson SC. The plant cell wall-decomposing machinery underlies the functional diversity of forest fungi. Science. 2011;333:762-5. 
38. Berka RM, Grigoriev IV, Otillar R, Salamov A, Grimwood J, Reid I, Ishmael N, John T, Darmond C, Moisan MC, Henrissat B, Coutinho PM, Lombard V, Natvig DO, Lindquist E, Schmutz J, Lucas S, Harris P, Powlowski J, Bellemare A, Taylor D, Butler G, de Vries RP, Allijn IE, van den Brink J, Ushinsky S, Storms R, Powell AJ, Paulsen IT, Elbourne LD, Baker SE, Magnuson J, Laboissiere S, Clutterbuck AJ, Martinez D, Wogulis M, de Leon AL, Rey MW, Tsang A. Comparative genomic analysis of the thermophilic biomass-degrading fungi Myceliophthora thermophila and Thielavia terrestris. Nat Biotechnol. 2011;29:922-7.

39. Lowry OH, Rosebrough NJ, Farr AL, Randall RJ. Protein measurement with the Folin phenol reagent. J Biol Chem. 1951;193:265-75.
40. Laemmli UK. Cleavage of structural proteins during the assembly of the head of bacteriophage T4. Nature. 1970;227:680-5.

41. Wisniewski JR, Zougman A, Nagaraj N, Mann M. Universal sample preparation method for proteome analysis. Nat Methods. 2009;6:359-62.

42. Michalski A, Damoc E, Hauschild JP, Lange O, Wieghaus A, Makarov A, Nagaraj N, Cox J, Mann M, Horning S. Mass spectrometry-based proteomics using $Q$ Exactive, a high-performance benchtop quadrupole Orbitrap mass spectrometer. Mol Cell Proteomics. 2011;10(M111):011015.

43. Domon B, Costello CE. A systematic nomenclature for carbohydrate fragmentations in FAB-MS/MS spectra of glycoconjugates. Glycoconj J. 1988:5:397-409.
Ready to submit your research? Choose BMC and benefit from:

- fast, convenient online submission

- thorough peer review by experienced researchers in your field

- rapid publication on acceptance

- support for research data, including large and complex data types

- gold Open Access which fosters wider collaboration and increased citations

- maximum visibility for your research: over $100 \mathrm{M}$ website views per year

At BMC, research is always in progress.

Learn more biomedcentral.com/submissions 